\title{
Barium titanate core - gold shell nanoparticles for hyperthermia treatments
}

\author{
This article was published in the following Dove Press journal: \\ International Journal of Nanomedicine \\ 27 June 2013 \\ Number of times this article has been viewed
}

\section{Elmira FarrokhTakin ${ }^{1,2}$ \\ Gianni Ciofani' \\ Gian Luigi Puleo' \\ Giuseppe de Vito ${ }^{3,4}$ \\ Carlo Filippeschi' \\ Barbara Mazzolai' \\ Vincenzo Piazza ${ }^{3}$ \\ Virgilio Mattoli'}

'Center for Micro-BioRobotics @SSSA, Fondazione Istituto Italiano di Tecnologia, Pontedera, Pisa, Italy;

${ }^{2}$ The Biorobotics Institute, Scuola Superiore Sant'Anna, Pontedera, Pisa, Italy; ${ }^{3}$ Center for Nanotechnology Innovation@NEST, Fondazione Istituto Italiano di Tecnologia, Pisa, Italy; ${ }^{4}$ NEST, Scuola Normale Superiore, Pisa, Italy
Correspondence: Elmira FarrokhTakin; Virgilio Mattoli

Center for Micro-BioRobotics @SSSA, Fondazione Istituto Italiano di Tecnologia, Viale Rinaldo Piaggio 34, 56025 Pontedera, Pisa, Italy

Tel +390508834I7

Fax +3905 0883402

Email elmira.farrokhtakin@iit.it; virgilio.mattoli@iit.it
Abstract: The development of new tools and devices to aid in treating cancer is a hot topic in biomedical research. The practice of using heat (hyperthermia) to treat cancerous lesions has a long history dating back to ancient Greece. With deeper knowledge of the factors that cause cancer and the transmissive window of cells and tissues in the near-infrared region of the electromagnetic spectrum, hyperthermia applications have been able to incorporate the use of lasers. Photothermal therapy has been introduced as a selective and noninvasive treatment for cancer, in which exogenous photothermal agents are exploited to achieve the selective destruction of cancer cells. In this manuscript, we propose applications of barium titanate core-gold shell nanoparticles for hyperthermia treatment against cancer cells. We explored the effect of increasing concentrations of these nanoshells $(0-100 \mu \mathrm{g} / \mathrm{mL})$ on human neuroblastoma SH-SY5Y cells, testing the internalization and intrinsic toxicity and validating the hyperthermic functionality of the particles through near infrared (NIR) laser-induced thermoablation experiments. No significant changes were observed in cell viability up to nanoparticle concentrations of $50 \mu \mathrm{g} / \mathrm{mL}$. Experiments upon stimulation with an NIR laser revealed the ability of the nanoshells to destroy human neuroblastoma cells. On the basis of these findings, barium titanate core-gold shell nanoparticles resulted in being suitable for hyperthermia treatment, and our results represent a promising first step for subsequent investigations on their applicability in clinical practice.

Keywords: barium titanate nanoparticles, gold nanoshells, NIR stimulation, human neuroblastoma

\section{Introduction}

Hyperthermia therapy, which entails the application of heat to treat disease conditions, has a long history dating back to ancient times. Hyperthermia is more precisely described as heating tissue to a temperature of $42^{\circ} \mathrm{C}-47^{\circ} \mathrm{C}$ for some tens of minutes, ${ }^{1}$ leading to irreversible damage in the case of cancerous cells. At this temperature range, because of their physiological characteristics, tumor cells may undergo either necrotic or apoptotic death. ${ }^{2-6}$ Yet, hyperthermia has been synergistic with conventional cancer therapy methods to attain more effective results., ${ }^{3,7}$

The main technological challenge of nanoscience and nanotechnology in recent years has concerned adding selectivity to the therapy, which has led to the idea of using exogenous heating agents. Since initial introduction of laser to hyperthermia, recent investigations in nanotechnology have generally focused on developing nanostructures with special optical properties that are appropriate for laser-induced hyperthermia, specifically metal nanostructures that demonstrate strong optical coupling of their plasmons with the laser light. ${ }^{8-13}$ The wavelength at which the surface plasmons resonate 
with the incident light (surface plasmon resonance), as well as the relative contribution of absorption or scattering to the total extinction spectra of the nanoparticles, strongly depends on the shape, size, type of metal, and surrounding dielectric environment, ${ }^{13-19}$ as well as on the particle orientation and interparticle interactions..$^{20}$ An increase in the size of the nanoparticles results in an increase of the extinction crosssection and the relative contribution of scattering to the total optical extinction. ${ }^{18}$ Plasmonic nanoparticles of a size much smaller than the wavelength of the light are better absorbers, and therefore prior candidates for localized photothermal heating, which is critical to invasive cancer treatment and tumor removal. ${ }^{21-23}$ These particles own a far-field extinction spectrum dominated by the dipole term from the series expansion of harmonic function of Mie theory. ${ }^{24}$ Larger nanoparticles instead demonstrate larger scattering crosssections ${ }^{25}$ that can be exploited for contrast enhancement in bioimaging. ${ }^{26-29}$ The resonant excitation of larger particles though, when of $100 \mathrm{~nm}$ or over in size, shows significant contributions from higher order multipole modes that create a broader far-field extinction spectra. The combination of the absorption and scattering properties, which depends on the size of the particle, allows nanoparticle-based integrated diagnostic imaging and therapy. ${ }^{30-32}$

During recent years, various nanostructures different in morphology, surface chemistry characteristics, chemical and physical properties, and therefore different optical features are intensively being investigated, each of which demonstrate their own appealing contribution to nearinfrared (NIR) photo-assisted hyperthermia therapy and diagnosis of cancer, as well as to other scientific fields. Where diagnosis is concerned, with the intention to reach the molecular level, a great number of recent studies has been concentrated on surface-enhanced spectroscopy methods, such as surface-enhanced Raman spectroscopy (SERS). This requires particles or structures that possess the so called hot spots to enhance the near electrical field and to respectively increase the output signal of the targeted species. Various nanoparticles and structures are being introduced and studied for this aim. ${ }^{33,34}$ Other studies, on the other hand, show results of second harmonic generation (SHG) response from plasmonic nanoshell structures ${ }^{35}$ and its dependence on the core dielectric constant as well as on the refractive index of the surrounding medium. Despite the fact that the main interest with plasmonic nanostructures is more concentrated on cancer therapy and diagnosis, these particles have had a significant influence on other fields of science as well. ${ }^{36}$ Numerous nanostructures different in shape, material, and structure, and therefore in chemical, physical, and optical properties have been and are being introduced and exploited for various applications. Among the variety of nanoparticles developed so far, nanoshells, introduced for the first time by Halas et al, present a new family of materials with tunable plasmon band, throughout the visible and into the infrared region of the electromagnetic spectrum. ${ }^{37-40}$ Being a hybrid structure, a variety of physical, chemical, and optical properties can be reached through a combination of different materials. These novel features can include as an instance the improved photocatalytic property of $\mathrm{ZnO}$ nanospheres upon being composed with a noble metal into nanoshell structure ${ }^{41}$ and many other examples in this regard. Therefore, nanoshells are still a subject of intense study either from a physical or chemical point of view. ${ }^{42}$ In the case of nanoshells, it is possible to modulate the relative contribution of the absorption or scattering of the particle by manipulating only the core/shell ratio and keeping the particle size unchanged. ${ }^{43,44}$ Nanoshells, as nanoscale heat sources, are currently being exploited in photothermal cell death and tumor destruction in vitro, ${ }^{45-47}$ with some other minor potential applications such as exogenous absorbers for tissue welding. ${ }^{48,49}$ In addition to being used as heating sources, these particles are either exploited as contrast agents, optically adjusted across a broad range of wavelengths in comparison with conventional molecular contrast agents. ${ }^{50}$ Moreover, these particles are biocompatible and non-photobleaching, ${ }^{51}$ and have been employed in various imaging modalities. ${ }^{51,52}$ To date, the nanoshell-assisted photothermal approach has been demonstrated to be effective in in-vitro and some in-vivo experiments on breast, brain, 9,53 and other tumor cell lines.

Following this line of research and our preliminary results on the synthesis of barium titanate core-gold shell (BaTiO $@$ goldshell) nanoparticles, ${ }^{54}$ in this manuscript we present an optimized synthesis of $\mathrm{BaTiO}_{3} @$ goldshell nanoparticles and demonstrate their potential ability for application in photothermal therapy. Recent results on the application of piezoelectric materials in biology, in particular barium titanate, ${ }^{55}$ motivated us to select this material as the core of our nanoshells to further study the potential characteristics resulting from merging piezoelectric and plasmonic properties. Furthermore, we intend to study more the SHG properties of barium titanate nanoparticles and the transformation of their second harmonic nonlinear response upon accommodating in a nanoshell structure. As described in the results and discussion sections, experiments conducted on neuroblastoma cell lines demonstrate that $\mathrm{BaTiO}_{3} @$ 
goldshell nanoparticles are effective heat-inducing agents. Furthermore, our studies show reasonable cytocompatibility of the particles and suggest their potential application for photothermal therapy.

\section{Material and methods}

Barium titanate $\left(\mathrm{BaTiO}_{3}\right)$ nanoparticles, $300 \mathrm{~nm}, 99.9 \%$ purity, were obtained from Nanostructured and Amorphous Materials Inc. (Houston, TX, USA). Hydrogen peroxide $\left(\mathrm{H}_{2} \mathrm{O}_{2}\right) 30 \%$ analytical grade, and sodium hydroxide $(\mathrm{NaOH})$ were purchased from Thermo Fisher Scientific (Waltham, MA, USA). Ammonia solution, 30\% $\left(\mathrm{NH}_{4} \mathrm{OH}\right)$, was purchased from Carlo Erba Reagenti SPA (Arese, Milano, Italy). (3-aminopropyl) triethoxysilane (APTES), 99.9\% hydrogen tetrachloroaurate trihydrate $\left(\mathrm{HAuCl}_{4}: 3 \mathrm{H}_{2} \mathrm{O}\right), 80 \%$ tetrakis(hydroxymethyl)phosphonium chloride (THPC), potassium carbonate (99.9\%) and sodium borohydride $\left(\mathrm{NaBH}_{4}\right)$ were purchased from Sigma-Aldrich (St Louis, $\mathrm{MO}, \mathrm{USA}$ ). $\mathrm{N}_{2}$-saturated distilled water was used in all steps. Dulbecco modified Eagle's medium/Ham's F12 (DMEM/ HF12), fetal bovine serum (FBS), trypsin, and phosphate buffered solution (PBS) were purchased from Euroclone S.p.A. (Pero, Milano, Italy) the LIVE/DEAD ${ }^{\circledR}$ viability assay was purchased from Life Technologies (Carlsbad, CA, USA); the WST-1 assay was purchased from Vinci Biochem Srl (Vinci, Firenze, Italy).

\section{Preparation of gold nanoshells}

\section{Functionalization of $\mathrm{BaTiO}_{3}$ nanoparticles}

The functionalization of $\mathrm{BaTiO}_{3}$ nanoparticles was carried out following our previous approach, ${ }^{54}$ with some modifications. Briefly, $120 \mathrm{mg}$ of $\mathrm{BaTiO}_{3}$ nanoparticles were added to $20 \mathrm{~mL}$ of $1 \mathrm{M}$ nitric acid in a plastic tube. The mixture was sonicated for 2 hours and left to stand overnight. The particles were washed with water until the solution reached approximately neutral $\mathrm{pH}$ and were then collected as a pellet by centrifugation at $5000 \mathrm{rpm}$ for 7 minutes. The final pellets were resuspended in water. Next, the particles were treated with $50 \mathrm{~mL}$ of hydrogen peroxide at $90^{\circ} \mathrm{C}$ for 4 hours, providing the surface with the hydroxyl groups required for further functionalization with an organosilane. ${ }^{56}$ The particles were then centrifuged under the same conditions as above and resuspended in $3 \mathrm{~mL}$ of water. The obtained $\mathrm{BaTiO}_{3}$ core nanoparticles were reacted with $140 \mu \mathrm{L}$ of APTES in the presence of $250 \mu \mathrm{L}$ of ammonium solution in $46 \mathrm{~mL}$ of anhydrous ethanol, thus providing amine groups on the surface for gold seeding in the subsequent step. The mixture was stirred for 3 hours at room temperature and for 2.5 hours at $78^{\circ} \mathrm{C}$, cooled and washed three times with ethanol to remove the reactants and then resuspended in ethanol for storage at $4^{\circ} \mathrm{C}$.

\section{Gold nanoparticles}

Aqueous solutions of colloidal gold nanoparticles with 1-2 nm diameters were prepared following the method proposed by Duff et al ${ }^{57,58}$ by reducing tetrachloroauric acid with THPC. The solution was gently stirred for 30 minutes and then kept in the refrigerator at $4^{\circ} \mathrm{C}$ in the dark for 4 weeks before being used in the following step.

\section{Attachment of colloidal gold seeds to amine-functionalized $\mathrm{BaTiO}_{3}$ nanoparticles}

Core $\mathrm{BaTiO}_{3}$ nanoparticles were seeded with the gold nanoparticles that were prepared in the previous step. Ten milliliters of the prepared colloidal gold nanoparticles was mixed with $1 \mathrm{~mL}$ of amine-functionalized $\mathrm{BaTiO}_{3}$ nanoparticles in a tube and left to stir gently for 2 hours. The seeded gold nanoparticles on the barium titanate surface promote shell formation in the following step. The mixture was centrifuged three times at $5000 \mathrm{rpm}$. The supernatant was decanted, and the reddish pellet was redispersed and sonicated in $3 \mathrm{~mL}$ of distilled water.

\section{Shell formation process}

To grow a gold shell on the core nanoparticles, a growth solution (gold hydroxide solution) containing gold reducible salt was prepared. ${ }^{59,60}$ Briefly, to a flask containing a $0.16 \mathrm{mmol}$ solution of potassium carbonate in $27.6 \mathrm{~mL}$ of distilled water, a $412.5 \mu \mathrm{L}$ aliquot of a $25 \mathrm{mM} \mathrm{HAuCl} \cdot 3 \mathrm{H}_{2} \mathrm{O}$ solution was added. The color of the solution gradually changed from transparent yellow to colorless over approximately 30 minutes. The resulting solution was left to stand overnight in the dark. Then, $26.7 \mu \mathrm{L}$ of the original gold-seeded barium titanate nanoparticles, diluted in $2.5 \mathrm{~mL}$ of water, was mixed under vigorous stirring with a $1.9 \mathrm{~mL}$ aliquot of gold hydroxide solution. After 10 minutes, $1 \mathrm{~mL}$ of ice-cold freshly prepared $0.06 \mathrm{M}$ of water solution of $\mathrm{NaBH}_{4}$ was added to the mixture and stirred for 5 minutes. The solution changed color from opaque light violet to transparent blue within 5 minutes. The resulting gold nanoshells (NS) were centrifuged three times and redispersed in $1 \mathrm{~mL}$ of water for use. A simplified scheme of gold shell formation structure is reported in Figure 1A.

The prepared particles were further studied for their optical and thermal features. The morphology of the gold coverage was examined by a dual beam (FIB/SEM) microscope, Helios (Hillsboro, OR, USA) NanoLab 600i, 
A

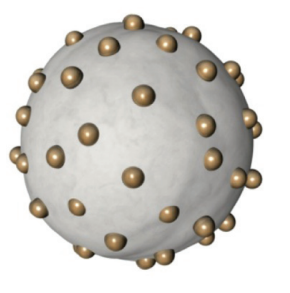

Gold seeded $\mathrm{BaTiO}_{3}$ core nanoparticle
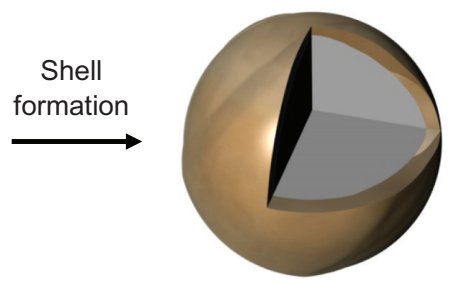

$\mathrm{BaTiO}_{3}$ core @ goldshell nanoparticle

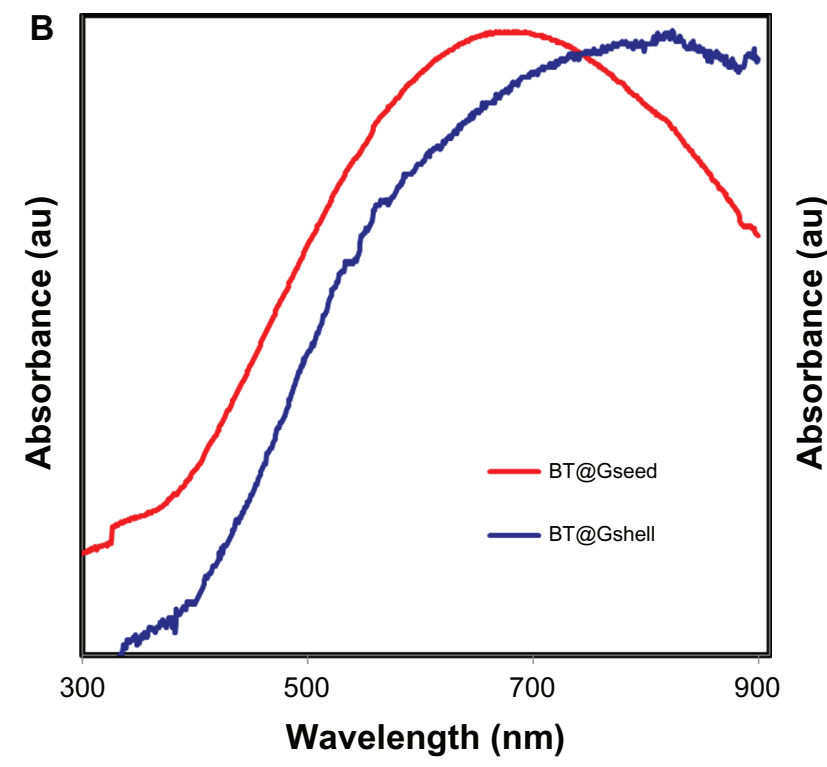

Figure I (A) Simplified scheme of gold-shell formation and structure of nanoparticles. (B) UV/Vis/NIR absorption spectrum of gold-seeded $\mathrm{BaTiO}_{3}$ nanoparticles (red line) and $\mathrm{BaTiO}_{3} @ g o l d-s h e l l$ nanoparticles (blue line).

Abbreviations: BT@Gseed, gold-seeded BaTiO3 nanoparticles; BT@Gshell, BaTiO3@gold-shell nanoparticles; NP, nanoparticles; UV/Vis/NIR, ultravioletvisible-near-infrared.

FEI. Samples were prepared by placing a drop of diluted nanoparticle solution on a silica wafer substrate and allowing the substrate to air-dry before observation.

The NIR absorption properties of the nanoparticles were studied by collecting the absorption spectra of their dispersion in water using a LAMBDA 45 PerkinElmer (Waltham, MA, USA) UV/Vis/NIR scanning spectrophotometer over a wavelength range from 400 to $900 \mathrm{~nm}$. Once it was verified that the sample had the appropriate NIR peak resonance $(\sim 800 \mathrm{~nm})$, more nanoparticles were produced for further biological experiments.

\section{Cytocompatibility evaluation and in-vitro testing}

Human neuroblastoma SH-SY5Y cells (ATCC CRL-2266) were cultured in DMEM/HF12 (1:1) with 10\% fetal calf serum, $100 \mathrm{IU} / \mathrm{mL}$ penicillin, $100 \mu \mathrm{g} / \mathrm{mL}$ streptomycin, and $2 \mathrm{mM} \mathrm{L-glutamine.} \mathrm{Cells} \mathrm{were} \mathrm{maintained} \mathrm{at} 37^{\circ} \mathrm{C}$ in a saturated humidity atmosphere containing $95 \%$ air $/ 5 \%$ $\mathrm{CO}_{2}$.

For viability testing, the SH-SY5Y cells were seeded in 96-well plates (5000 cells per well) and incubated with increasing concentrations of nanoshells $(0,10,20,50$, and $100 \mu \mathrm{g} / \mathrm{mL}$ ). At 24 and 72 hours from the beginning of treatment, cell metabolism was assessed with the WST-1 assay (2-(4-iodophenyl)-3-(4-nitophenyl)-5-(2,4-disulfophenyl)$2 \mathrm{H}$-tetrazoilium monosodium salt, provided in a pre-mixed electro-coupling solution). Cell cultures were treated with $100 \mu \mathrm{L}$ of culture medium with $10 \mu \mathrm{L}$ of the pre-mixed solution added for 2 hours, and the absorbance was read at $450 \mathrm{~nm}$ with a microplate reader (Victor3; PerkinElmer). A further, qualitative evaluation of nanoshell cytocompatibility was performed with the LIVE/DEAD viability/ cytotoxicity kit after 72 hours of treatment. The kit contains calcein AM (4 mM in anhydrous DMSO) and ethidium homodimer-1 (EthD-1, $2 \mathrm{mM}$ in DMSO/ $\mathrm{H}_{2} \mathrm{O}$ 1:4 (v/v)) and allows for the discrimination between live cells (greenfluorescent stained by calcein) and dead cells (red-fluorescent stained by EthD-1). Cultures were rinsed with PBS, treated for 10 minutes at $37^{\circ} \mathrm{C}$ with $2 \mu \mathrm{M}$ calcein $\mathrm{AM}$ and $4 \mu \mathrm{M}$ EthD-1 in DMEM, and finally observed with an inverted fluorescence microscope (TE2000U, Nikon, Tokyo, Japan) equipped with a cooled CCD camera (DS-5MC USB, Nikon). Same experiments were also carried out on differentiating SH-SY5Y cells, cultured for 3 days in a low-serum medium (1\%) supplemented with all-trans retinoic acid $(20 \mu \mathrm{M})$ to evaluate cytocompatibility on a model of neuronal cells.

Nanoparticle internalization has been investigated in cells treated for 24 hours with $50 \mu \mathrm{g} / \mathrm{mL}$ of nanoshells by multimodal microscopy with an in-plane resolution of approximately $300 \mathrm{~nm}$ and a resolution of $1 \mu \mathrm{m}$ along the optical axis. Coherent anti-Stokes Raman scattering (CARS) tuned to the $\mathrm{CH}_{2}$ bond Raman shift $\left(2850 \mathrm{~cm}^{-1}\right)$ has been exploited to image individual cells. The sum-frequency signals generated by the nanoshells at approximately $450 \mathrm{~nm}$ by the combination of $800 \mathrm{~nm}$ pump-and-probe pulses with $1045 \mathrm{~nm}$ Stokes photons allowed for the positions of the nanoshells to be determined.

In-vitro thermoablation experiments were performed after incubating the cells for 6 hours with $50 \mu \mathrm{g} / \mathrm{mL}$ of nanoshells. Thereafter, the cultures underwent the LIVE/ DEAD assay procedure and underwent laser stimulation using a $785 \mathrm{~nm}$ laser diode (OBIS 785 LX, Coherent, Santa Clara, CA, USA) overlapping with the wavelength at the maximum surface plasmon resonance (SPR) absorption of the nanoparticles. The nominal power of laser was 
$50 \mathrm{~mW}$, and the measured power at the sample surface was approximately $10 \mathrm{~mW}$, focused on a spot of approximately $0.04 \mathrm{~mm}^{2}$ for a power density of $250 \mathrm{~mW} / \mathrm{mm}^{2}$. The laser was integrated into the fluorescence microscope, thus offering the advantage of real-time tracking of cell damage. Experiments were performed by applying the laser light for 3 minutes. Control experiments were conducted using the same laser light source to stimulate non-nanoparticle treated cultures.

\section{Statistical analysis}

Analysis of the data was performed by an analysis of variance (ANOVA) followed by Student's $t$-test to test for significance, which was set at 5\%. The WST-1 tests were performed in six replicates; all the remaining assays were performed in triplicate if not otherwise specified. In all cases, three independent experiments were conducted. The results are presented as the mean value \pm standard deviation.

\section{Results and discussion \\ Nanoshells and their optical properties}

Nanoshells with a core diameter of $300 \mathrm{~nm}$ and an approximate shell thickness of $20 \mathrm{~nm}$ were designed to have SPR peak absorption in the NIR region. As seen in Figure 1B, a significant spectral red shift with respect to the absorption spectra of the gold-seeded particles (red line) can be interpreted as an increase in the gold coverage, indicating shell formation (blue line). Figure 1B illustrates the maximum absorption at $820 \mathrm{~nm}$ for the final nanoparticles, where the large bandwidth of the peak is associated with the size of the core. ${ }^{17}$ According to the literature, very small, fresh THPC gold nanoparticles do not establish plasmonic features; ${ }^{61,62}$ nevertheless, aging the gold colloid for a period of 3-4 weeks causes an increase in the size of the particles. The attachment of gold seeds to $\mathrm{BaTiO}_{3}$ cores was achieved through the existing electrostatic attraction between the positively charged amino-functionalized core particles (through APTES moieties) and the negatively charged gold nanoparticles. ${ }^{63} \mathrm{In}$ general, in an aqueous medium, the measured zeta potential of colloidal particles is strongly affected by the $\mathrm{pH}$ of the solution. This fact was taken into account to obtain uniform seeding.

Figure 2A shows a number of partially covered core particles with gold seeds having significant coverage uniformity at this intermediate step of shell growth. Consistent with previous observations, ${ }^{63,64}$ these nanoparticles serve as nucleus sites for the growth of a continuous gold shell by reducing additional gold precursors in their proximity. The reduction

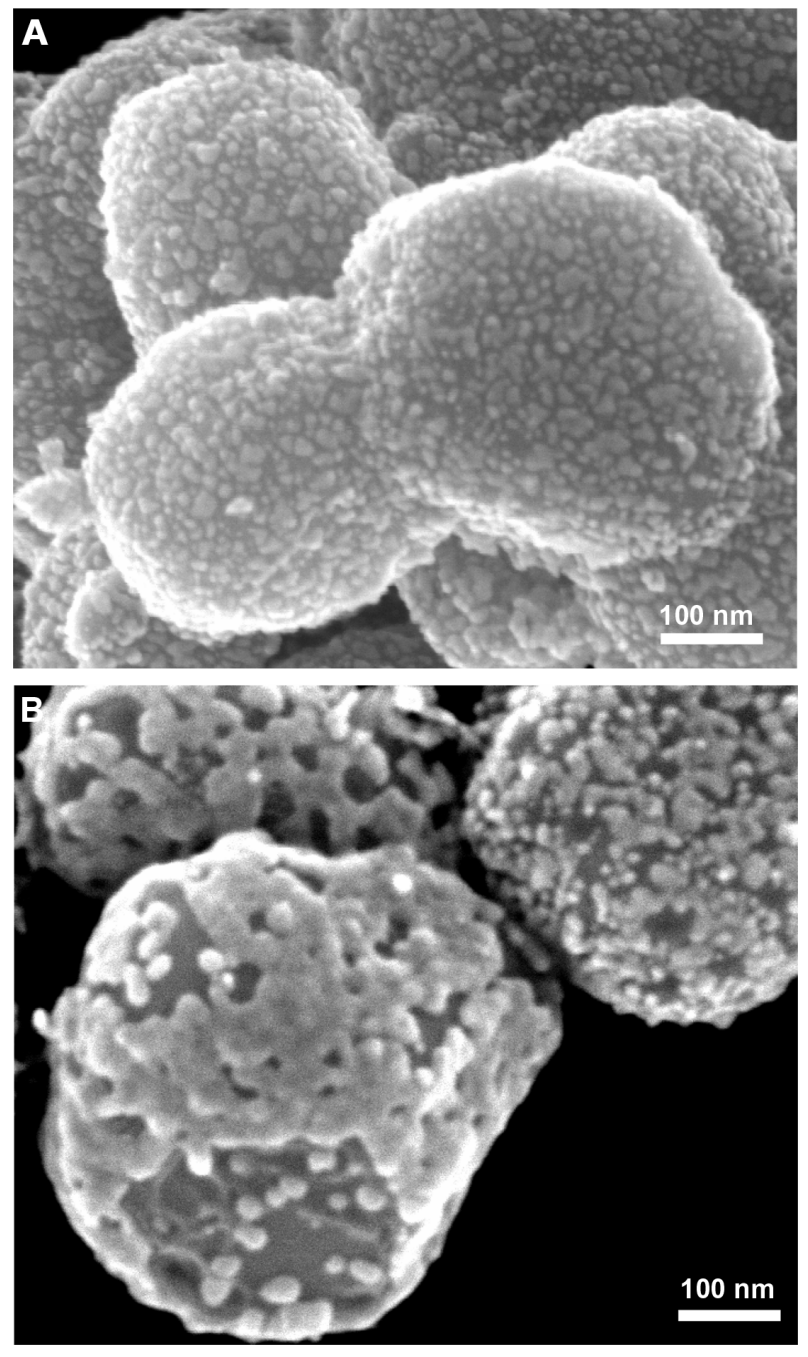

Figure 2 Scanning electron microscopy image of $\mathrm{BaTiO}_{3}$ nanoparticles (A) seeded with gold and (B) shell formation.

of the gold in the last step allows the seed nanoparticles on the surface to grow and merge, thereby causing a systematic red shift of the SPR into the NIR $(820 \mathrm{~nm})$ region. ${ }^{39,63}$ The coalescence and merging of individual and separated gold nanoparticles into a shell are shown in Figure 2B, confirming shell formation, in this case with a smooth-looking shell. A scanning electron microscopy image and energy dispersive X-ray analysis on a single nanoshell showing its elementary composition is also reported (see Figure S1). As the dual beam images demonstrate, the core particles are rather spheroid with about $300 \mathrm{~nm}$ diameter and approximately $20 \mathrm{~nm}$ shell thickness.

To attain the most uniform shell layer, the surface of the core nanoparticles must be pre-treated with acid and then hydrogen peroxide, because of the essential role of having homogenous silanization and therefore seeding. When $\mathrm{BaTiO}_{3}$ nanoparticles are exposed to acidic solution, the 
$\mathrm{BaCO}_{3}$ impurities present on the particle surface dissolve in water, leaving the particle surface similar in structure to a classic metal oxide lattice $\left(\mathrm{eg}, \mathrm{TiO}_{2}\right)$. The $\mathrm{pH}$ of acidic solution affects the amount of $\mathrm{Ba}^{2+}$ leaching from the surface of the particle. ${ }^{65}$ Placing the core particles in contact with an aqueous solution of hydrogen peroxide in optimized conditions provides the surface of the particles with an adequate number of hydroxyl groups that are essential for the attachment of APTES molecules. However, in the optimized conditions, $\mathrm{H}_{2} \mathrm{O}_{2}$ removes the adsorbed carbonate from the surface of the nanoparticle in a manner comparable to what occurs in a weak aqueous acetic acid solution. ${ }^{66}$ As a consequence, when the particles were placed in $\mathrm{H}_{2} \mathrm{O}_{2}$ immediately after treatment with acid (nitric acid in our case), skipping the washing step or failing to properly wash the particles to reach neutral $\mathrm{pH}$, the resulting mixture appeared yellowish with large clod-like aggregations of particles that were not easily broken. On the basis of these observations, the combination of acid and $\mathrm{H}_{2} \mathrm{O}_{2}$ causes an excessive loss of barium ions that leads to the degradation of the particle surface and its structure.

\section{Nanoshell cytocompatibility and internalization}

Cell viability was investigated with the LIVE/DEAD viability/cytotoxicity kit. The results on the compatibility of nanoshells revealed no evidence of cell membrane damage after the cells were treated with concentrations up to $50 \mu \mathrm{g} / \mathrm{mL}$ (Figure $3 \mathrm{~A}$ ) for 72 hours of incubation, demonstrating viabilities comparable to the control cultures (less than $5 \%$ of red, ie, necrotic, cells). At $100 \mu \mathrm{g} / \mathrm{mL}$, however, a consistent decrement of cell density and increased cell death were observed.

These results were quantitatively confirmed by the WST-1 assay, which demonstrated excellent metabolic activity in cells treated with concentrations of nanoshells up to $50 \mu \mathrm{g} / \mathrm{mL}$ (Figure $3 \mathrm{~B}$ ) and no statistically significant decrement of viability compared with the controls after both 24 and 72 hours. After 72 hours, a highly tangible decrease of cell metabolism was observed in cells treated with $100 \mu \mathrm{g} / \mathrm{mL}$ of nanoshells (about 40\%, $P<0.05$ ). Analogous results have been achieved on differentiating SH-SY5Y cells, as a model of human neurons. No significant variation in metabolic activity, viability, and differentiation status was highlighted in cells treated with $0-50 \mu \mathrm{g} / \mathrm{mL}$ of nanoshells (see Figure S2).

Figure 4 shows results of internalization assessment: a composite image is reported, where the green channel
A
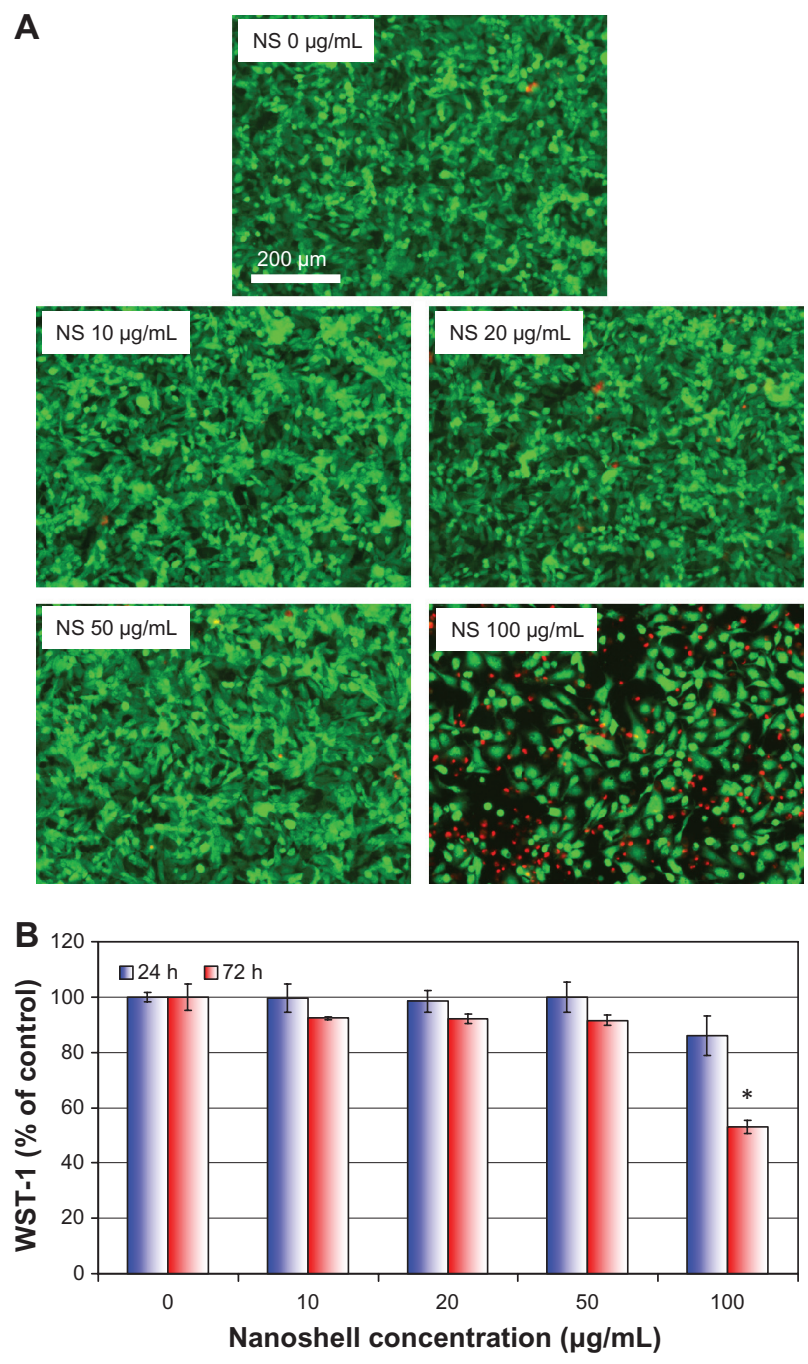

Figure 3 Cytocompatibility results: (A) LIVE/DEAD ${ }^{\circledR}$ assay and (B) WST-I assay at 24 and 72 hours; * denotes $P<0.05$.

maps the intensity of the CARS signal, and the red channel indicates the intensity of the sum-frequency signals. The dark spots are the shadows of nanoshells below or above the imaging plane. Example of CARS Z-stack acquisition is also reported (see Figure S3).

Considering all the collected data, an operative dose of $50 \mu \mathrm{g} / \mathrm{mL}$ was thus used for the following experiments.

\section{Photothermal ablation}

Gold nanoshells have been demonstrated to be suitable heating agents for photothermal ablation of cancerous cells. ${ }^{64}$ Halas and co-workers demonstrated that gold nanoshells can be used for plasmonic photothermal therapy in the NIR region with two different modes for targeting the cells: passive $e^{25,50}$ and active..$^{29}$ In addition to the two modes, another approach for targeting tumor cells is the enhanced permeability and retention (EPR) effect. According to the EPR effect, the 


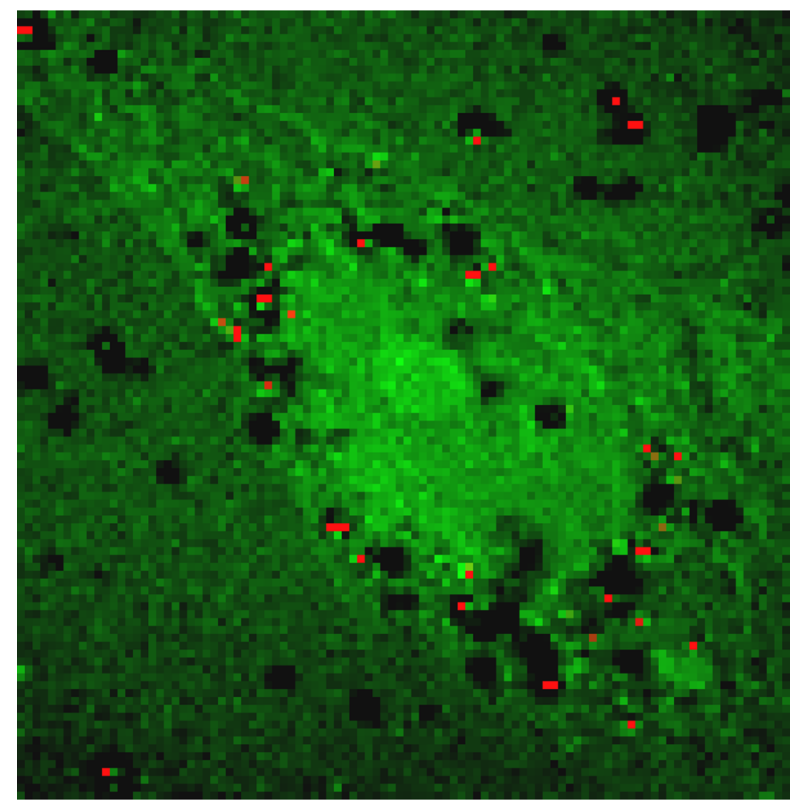

Figure 4 Multimodal image of an individual cell. The green channel maps the intensity of the coherent anti-Stokes Raman scattering signals from the $\mathrm{CH}_{2}$ bonds; the red channel indicates the sum-frequency signals from the nanoshells. The field is $50 \mu \mathrm{m} \times 50 \mu \mathrm{m}$.

concentration of nanoparticles that accumulate in tumor tissues is greater than that in normal tissues or organs. ${ }^{67,68}$ Since it was discovered, the EPR effect has been recognized as the standard criterion for designing new anticancer agents. ${ }^{69}$ It is assumed that based on the EPR effect, small nanoparticles ( $<400 \mathrm{~nm}$ ), including nanoshells, selectively accumulate in the tumor tissue by the passive extravasation associated with the leaky tumor vascularity. ${ }^{28,30,69}$ In theory, upon accumulation within tumors, nanoshells interfere in cell damage and aid in cancer/tumor treatment by absorbing NIR light and transforming it into heat as a result of their plasmonic characteristics. When using nanoshells that are designed to be scatterers (higher scattering cross-sections), cancerous cells could be detected even at an early stage. Here, we provide an in-vitro demonstration of the thermal ablation of neuroblastoma cell-lines using nanoshells designed to absorb NIR light.

Figure 5 shows cells incubated with nanoshells and stained with the LIVE/DEAD stain before and after treatment with the NIR laser. The ability of nanoshells to cause cell death under NIR light irradiation is demonstrated in the fluorescence images. Surviving and dead cells are shown in green and red, respectively. A bright field image of the sample and an image of the spot of laser exposure are also included in Figure 5. The left column illustrates cells that were incubated with nanoshells prior to exposure to the laser light in the bright field mode (Figure 5A) and in the

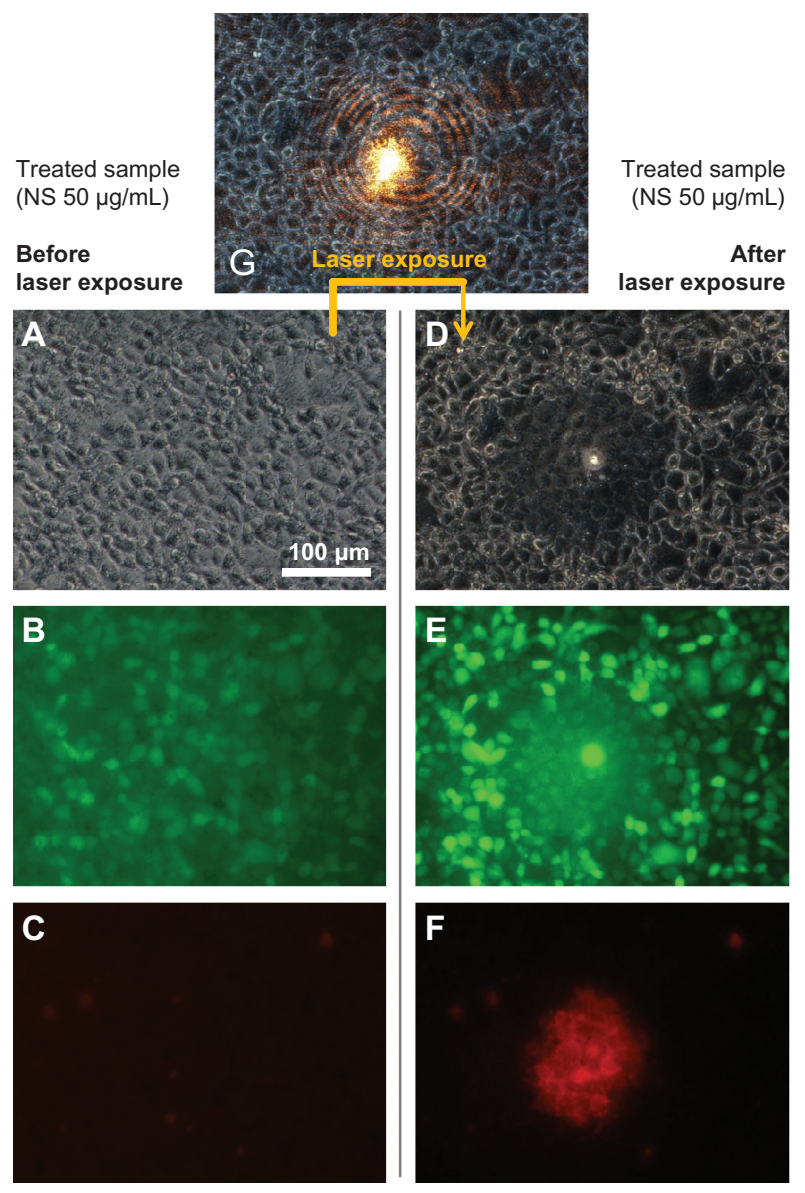

Figure 5 Photo-induced thermal ablation of neuroblastoma cells incubated with nanoshells prior to (left main column) and after (right main column) exposure to laser light. Cells are labeled with calcein (live cells in green) and with EthD-I (dead cells in red).

fluorescence mode, indicating live (green) cells (Figure 5B) and dead (red) cells (Figure 5C), respectively. After exposure to laser light, significant cell death occurred, as shown in Figure 5E. No live cells remained within the spot of laser exposure or its vicinity, which is evident by the hole-like spot in the center of the green fluorescent background. The red spherical stain in Figure 5F corresponds to this mentioned zone and shows the dead cells within the border of the spot of laser exposure. Figure 5D shows a more tangible image of dead cells in the spot of laser exposure. Further control experiments to verify the influence of the laser alone were performed on cells not incubated with the nanoshells prior to exposure to laser light. No cell death is evident in the results of these experiments; cell damage is not observed in either of the control cases, confirming that highly effective, localized, and selective photothermal therapy would result from combining nanoshells and laser light at the appropriate wavelength for SPR absorption of the particles. Images for negative control on cells nonin- 
cubated with nanoshells and treated with laser are shown in Figure S4.

\section{Conclusion}

Previous work by our group investigated $\mathrm{BaTiO}_{3}$ nanoparticles and their potential applications in biology. ${ }^{70}$ We recently reported our preliminary research on the development of $\mathrm{BaTiO}_{3} @$ goldshell nanoparticles. ${ }^{56}$ In the present study, we demonstrated how the surface-plasmon-based-photoabsorption characteristics of these particles can effectively induce cell death selectively within the spot of laser exposure. The nanoshells were prepared through an accurate process combining molecular self-assembly and colloidal growth chemistry ${ }^{71}$ and showed suitable cytocompatibility at concentrations up to $50 \mu \mathrm{g} / \mathrm{mL}$. The prepared nanoparticles were passively accumulated in cells and irradiated by an NIR laser. Localized photo-induced cell damage resulted from the studies carried out on neuroblastoma cell-lines. Future studies will be focused on addressing targeted delivery of nanoshells to specific cells and/or tissues, and on synergetic imaging and therapy of tumor cells. Thanks to their high second-order nonlinear optical susceptibility, $\mathrm{BaTiO}_{3}$ nanoparticles are in fact considered good candidates to be exploited in SHG techniques. $\mathrm{BaTiO}_{3}$ nanoparticles show substantial advantages over other SHG labeling probes, such as their ideal signal transfer, ${ }^{73,74}$ that make them suitable for use in in-vivo imaging. The simultaneous exploitation of piezoelectricity, SHG, and plasmon resonance, render therefore $\mathrm{BaTiO}_{3} @$ goldshell nanoparticles a promising theragnostic device in cancer research.

\section{Executive summary}

1. In this paper, we describe the synthesis and characterization of BaTiO3@goldshell nanoparticles.

2. An optimal dose range of BNNTs $(0-50 \mu \mathrm{g} / \mathrm{mL})$ was identified for their in-vitro administration to cell cultures.

3. Nanoparticle internalization by neuroblastoma cells was verified through CARS.

4. The optical response of the prepared nanoshells was exploited to achieve cell destruction through hyperthermia following NIR laser stimulation.

\section{Disclosure}

The authors report no conflicts of interest in this work.

\section{References}

1. Svaasand LO, Gomer CJ, Morinelli E. On the physical rationale of laser induced hyperthermia. Lasers Med Sci. 1990;5(2):121-128.
2. Huang X, Jain PK, El-Sayed IH, El-Sayed MA. Plasmonic photothermal therapy (PPTT) using gold nanoparticles. Lasers Med Sci. 2008;23: 217-228.

3. Wolf P. Innovations in Biological Cancer Therapy: A Guide for Cancer Patients and their Relatives. Hannover: NaturaSanitas; 2008.

4. Yonezawa M, Otsuka T, Matsui N, et al. Hyperthermia induces apoptosis in malignant fibrous histiocytoma cells in vitro. Int $J$ Cancer. 1996;66(3): 347-351.

5. Issels RD. Hyperthermia adds to chemotherapy. Eur J Cancer. 2008;44:2546-2554.

6. Harmon BC, Corder AM, Collins JR, et al. Cell death induced in murine mastocytoma by $42^{\circ} \mathrm{C}-47^{\circ} \mathrm{C}$ heating in vitro: evidence that the form of death changes from apoptosis to necrosis above a critical heat load. Int Radiat Oncol Biol. 1990;58:845-858.

7. Dollinger M. Everyone's Guide to Cancer Therapy: How Cancer is Diagnosed, Treated, and Managed Day to Day. Kansas City, MO: Andrews McMeel Publishing; 2002:98-100.

8. Cheng FY, Chen CT, Yeh CS. Comparative efficiencies of photothermal destruction of malignant cells using antibody coated silica@Au nanoshells, hollow Au/Ag nanospheres and Au nanorods. Nanotechnology. 2009;20(42):425104.

9. Schwartz JA, Shetty AM, Price RE, et al. Feasibility study of particleassisted laser ablation of brain tumors in orthotopic canine model. Cancer Res. 2009;69:1659-1667.

10. Liu SY, Liang ZS, Gao F, Luo SF, Lu GQ. In vitro photothermal study of gold nanoshells functionalized with small targeting peptides to liver cancer cells. J Mater Sci Mater Med. 2010;21(2):665-674.

11. Day ES, Thompson PA, Zhang L, et al. Nanoshell-mediated photothermal therapy improves survival in a murine glioma model. J Neurooncol. 2010;104(1):55-63.

12. Kennedy LC, Bickford LR, Lewinski NA, et al. A new era for cancer treatment: gold-nanoparticle-mediated thermal therapies. Small. 2011;7(2):169-183.

13. El-Sayed MA. Some interesting properties of metals confined in time and nanometer space of different shapes. Acc Chem Res. 2001;34(4): 257-264.

14. Lal S, Link S, Halas NJ. Nano-optics from sensing to waveguiding. Nat Photonics. 2007;1:641-648.

15. Oldenburg SJ, Jackson JB, Westcott SL, Halas NJ. Infrared extinction properties of gold nanoshells. Appl Phys Lett. 1999;75(19):2897-2899.

16. Lee KS, El-Sayed MA. Gold and silver nanoparticles in sensing and imaging: sensitivity of plasmon response to size, shape, and metal composition. J Phys Chem B. 2006;110(39):19220-19225.

17. Peña $\mathrm{O}, \mathrm{Pal} U$, Rodríguez-Fernández L, Crespo-Sosa A. Linear optical response of metallic nanoshells in different dielectric media. J Opt Soc Am B. 2008;25(8):1371-1379.

18. Jain PK, Lee KS, El-Sayed IH, El-Sayed MA. Calculated absorption and scattering properties of gold nanoparticles of different size, shape, and composition: applications in biological imaging and biomedicine. J Phys Chem B. 2006;110(14):7238-7248.

19. Liz-Marzán LM, Giersig M, Mulvaney P. Synthesis of nanosized goldsilica core-shell particles. Langmuir. 1996;12(18):4329-4335.

20. Liz-Marzán LM. Tailoring surface plasmons through the morphology and assembly of metal nanoparticles. Langmuir. 2006;22(1):32-41.

21. O’Neal DP, Hirsch LR, Halas NJ, Payne JD, West JL. Photo-thermal tumor ablation in mice using near infrared-absorbing nanoparticles. Cancer Lett. 2004;209(2):171-176.

22. Lowery AR, Gobin AM, Day ES, Halas NJ, West JL. Immunonanoshells for targeted photothermal ablation of tumor cells. Int J Nanomedicine. 2006;1(2):149-154.

23. Huang X, Jain PK, El-Sayed IH, El-Sayed MA. Determination of the minimum temperature required for selective photothermal destruction of cancer cells with the use of immunotargeted gold nanoparticles. Photochem Photobiol. 2006;82(2):412-417.

24. Oldenburg SJ, Hale GD, Jackson JB, Halas NJ. Light scattering from dipole and quadropole nanoshell antennas. Appl Phys Lett. 1999;75(8): 1063-1065. 
25. Link S, El-Sayed MA. Size and temperature dependence of the plasmon absorption of colloidal gold nanoparticles. J Phys Chem B. 1999;103(21):4212-4217.

26. Loo C, Lin A, Hirsch L, et al. Nanoshell-enabled photonics-based imaging and therapy of cancer. Technol Cancer Res Treat. 2004;3(1):33-40.

27. Lin AW, Lewinski NA, West JL, Halas NJ, Drezek RA. Optically tunable nanoparticle contrast agents for early cancer detection: modelbased analysis of gold nanoshells. J Biomed Opt. 2005;10(6):064035.

28. Puvanakrishnan P, Park J, Diagaradjane P, Schwartz JA, et al. Near-infrared narrow-band imaging of gold/silica nanoshells in tumors. J Biomed Opt. 2009;14(2):024044.

29. Bickford LR, Agollah G, Drezek R, Yu TK. Silica-gold nanoshells as potential intraoperative molecular probes for HER2-overexpression in ex vivo breast tissue using near-infrared reflectance confocal microscopy. Breast Cancer Res Tr. 2010;120(3):547-555.

30. Loo C, Lowery A, Halas NJ, West JL, Drezek R. Immunotargeted nanoshells for integrated cancer imaging and therapy. Nano Lett. 2005;5(4): 709-711.

31. Kim J, Park S, Lee JE, et al. Designed fabrication of multifunctional magnetic gold nanoshells and their application to magnetic resonance imaging and photothermal therapy. Angewandte Chemie. 2006;45(46): 7754-7758.

32. Lal S, Clare SE, Halas NJ. Nanoshell-enabled photothermal cancer therapy: impending clinical impact. Acc Chem Res. 2008;41(12): 1842-1851.

33. Smitha SL, Gopchandran KG, Smijesh N, Philip R. Size-dependent optical properties of Au nanorods. Prog Nat Sci Mater Int. 2013;23(1): 36-43.

34. Goh MS, Lee YH, Pedireddy S, et al. A chemical route to increase hot spots on silver nanowires for surface-enhanced Raman spectroscopy application. Langmuir. 2012;28(40):14441-14449.

35. Butet J, Russier-Antoine I, Jonin C, Lascoux N, Benichou E, Brevet P-F. Effect of the dielectric core and embedding medium on the second harmonic generation from plasmonic nanoshells: tunability and sensing J Phys Chem C. 2013;117:1172-1177.

36. Alessandri I, Ferroni M, Depero LE. Plasmonic heating-assisted transformation of $\mathrm{SiO}_{2} / \mathrm{Au}$ core/shell nanospheres (Au nanoshells): caveats and opportunities for SERS and direct laser writing. Plasmonics. 2013;8: 129-132.

37. Oldenburg SJ, Averitt RD, Westcott SL, Halas NJ. Nanoengineering of optical resonances. Chem Phys Lett. 1998;288(2-4):243-247.

38. Liu S, Liang Z, Gao F, et al. A facile approach to the synthesis of gold nanoshells with near infrared responsive properties. Chin J Chem. 2009;27(6) 1079-1085.

39. Shi W, Sahoo Y, Swihart MT, Prasad PN. Gold nanoshells on polystyrene cores for control of surface plasmon resonance. Langmuir. 2005;21(4): 1610-1617.

40. Hu M, Chen J, Li ZY, et al. Gold nanostructures: engineering their plasmonic properties for biomedical applications. Chem Soc Rev. 2006;35: 1084-1094.

41. Guo X-H, Ma J-Q, Ge H-G. Preparation, characterization and photocatalyic performance of pear-shaped $\mathrm{ZnO} / \mathrm{Ag}$ core-shell submicrospheres. J Phys Chem Solids. 2013;74:784-788.

42. Brio-Silva AM, Sobra-Filho RG, Barbosa-Silva R, de Araujo CB, Galembeck A, Brolo AG. Improved synthesis of gold and silver nanoshells. Langmuir. 2013;29:4366-4372.

43. Averitt RD, Westcott SL, Halas NJ. Linear optical properties of gold nanoshells. J Opt Soc Am B. 1999;16(10):1824-1832.

44. Nehl CL, Grady NK, Goodrich GP, Tam F, Halas NJ, Hafner JH. Scattering spectra of single gold nanoshells. Nano Lett. 2004;4(12):2355-2359.

45. Yang TD, Cho W, Yoon TH, et al. Real-time phase-contrast imaging of photothermal treatment of head and neck squamous cell carcinoma: an in vitro study of macrophages as a vector for the delivery of gold nanoshells. J Biomed Opt. 2012;17(12):128003.

46. Stem JM, Stanfield J, Kabbani W, Hsieh JT, Cadeddu JA. Selective prostate cancer thermal ablation with laser activated gold nanoshells. J Urol. 2008;179(2):748-753.
47. Stem JM, Cadeddu JA. Emerging use of nanoparticles for the therapeutic ablation of urologic malignancies. Urol Oncol-Semin Ori.2008; 26(1):93-96.

48. Gobin AM, O’Neal DP, Watkins DM, Halas NJ, Drezek R, West JL. Near infrared laser-tissue welding using nanoshells as an exogenous absorber. Laser Surg Med. 2005;37(2):123-129.

49. Braun GB, Pallaoro A, Wu G, et al. Laser-activated gene silencing via gold nanoshells-iRNA conjugates. ACS Nano. 2009;3(7):2007-2015.

50. Yguerabidea J, Yguerabide EE. Light-scattering submicroscopic particles as highly fluorescent analogs and their use as tracer labels in clinical and biological applications. Anal. Biochem. 1998;262(2):137-156.

51. Raub CB, Orwin EJ, Haskel R. Immunogold labeling to enhance contrast in optical coherence microscopy of tissue engineered corneal constructs. Conf Proc IEEE Eng Med Biol Soc. 2004;2:1210-1213.

52. Sokolov K, Follen M, Aaron J, et al. Real-time vital optical imaging of precancer using anti-epidermal growth factor receptor antibodies conjugated to gold nanoparticles. Cancer Res. 2003;63(9): 1999-2004.

53. Bernardi RJ, Lowery AR, Thompson PA, Blaney SM, West JL. Immunonanoshells for targeted photothermal ablation in medulloblastoma and glioma: an in vitro evaluation using human cell lines. J Neurol. 2008;86(2):165-172.

54. FarrokhTakin E, Ciofani G, Gemmi M, Piazza V, Mazzolai B, Mattoli V. Synthesis and characterization of new barium titanate core-gold shell nanoparticles. Colloid Surf A. 2012;415:247-254.

55. Ciofani G, Danti S, D'Alessandro D, et al. Enhancement of neurite outgrowth in neuronal-like cells following boron nitride nanotubemediated stimulation. ACS Nano. 2010;4(10):6267-6277.

56. Chang SJ, Liaoa WS, Cioua CJ, Leec JT, Lia CC. An efficient approach to derive hydroxyl groups on the surface of barium titanate nanoparticles to improve its chemical modification ability. J Colloid Interface Sci. 2009;329(2):300-305.

57. Duff DG, Baiker A, Edwards PP. A new hydrosol of gold clusters. 1. Formation and particle size variation. Langmuir. 1993;9(9): 2301-2309.

58. Duff DG, Baiker A, Gameson I, Edwards PP. A new hydrosol of gold clusters. 2. A comparison of some different measurement techniques. Langmuir. 1993;9(9):2310-2317.

59. Westcott SL, Oldenburg SJ, Lee TR, Halas NJ. Formation and adsorption of clusters of gold nanoparticles onto functionalized silica nanoparticle surfaces. Langmuir. 1998;14(19):5396-5401.

60. Park S, Park M, Han P, Lee S. Relative contributions of experimental parameters to NIR-absorption spectra of gold nanoshells. J Ind Eng Chem. 2007;13(1):65-70.

61. Leff DV, Brandt L, Heath JR. Synthesis and characterization of hydrophobic, organically-soluble gold nanocrystals functionalized with primary amines. Langmuir. 1996;12(20):4723-4730.

62. Yonga KT, Sahooa Y, Swiharta MT, Prasad PN. Synthesis and plasmonic properties of silver and gold nanoshells on polystyrene cores of different size and of gold-silver core-shell nanostructures. Colloid Surf A. 2006;290(1-3):89-105.

63. Pham T, Jackson JB, Halas NJ, Lee TR. Preparation and characterization of gold nanoshells coated with self-assembled monolayers. Langmuir. 2002;18(12):4915-4920.

64. O’Neala DP, Hirschb LR, Halas NJ, Paynea JD, West JL. Photothermal tumor ablation in mice using near infrared absorbing nanoshells. Cancer Lett. 2004;209(2):171-176.

65. Yoon DH, Lee BI, Badheka P, Wang X. Barium ion leaching from barium titanate powder in water. J Mater Sci Mater Electron. 2003;14: $165-169$.

66. Kolen'ko YV, Kovnir KA, Neira IS, et al. A novel, controlled and highyield solvothermal drying route to nanosized barium titanate powders. J Phys Chem C. 2007;111(20):7306-7318.

67. Matsumura Y, Maeda H. A new concept for macromolecular therapeutics in cancer chemotherapy: mechanism of tumoritropic accumulation of proteins and the antitumor agent smancs. Cancer Res. 1986;46:6387-6392. 
68. Iwai K, Maeda H, Konno T. Use of oily contrast medium for selective drug targeting to tumor: enhanced therapeutic effect and X-ray image. J Cancer Res. 1984;44:2115-2121.

69. Muggia FM. Doxorubicin-polymer conjugates: further demonstration of the concept of enhanced permeability and retention. Clin Cancer Res. 1999;5:7-8.

70. Ciofani G, Danti S, Moscato S, et al. Preparation of stable dispersion of barium titanate nanoparticles: potential applications in biomedicine. Colloids Surf B. 2010;76(2):535-543.

71. Oldenburg SJ, Averitt RD, Westcott SL, Halas NJ. Nanoengineering of optical resonances. Chem Phys Lett. 1998;288(2-4):243-247.
72. Nicua L, Guirardela M, Chambossea F, et al. Resonating piezoelectric membranes for microelectromechanically based bioassay: detection of streptavidin-gold nanoparticles interaction with biotinylated DNA. Sensor Acuat B-Chem. 2005;110(1):125-136.

73. Frey MH, Payne DA. Grain-size effect on structure and phase transformation for barium titanate. Phys Rev B. 1996;54(5): 3158-3168.

74. Pantazis P, Maloney J, Wu D, Fraser SE. Second harmonic generating (SHG) nanoprobes for in vivo imaging. Proc Natl Acad Sci U S A. 2010;107(33):14535-14540. 


\section{Suplementary figures}

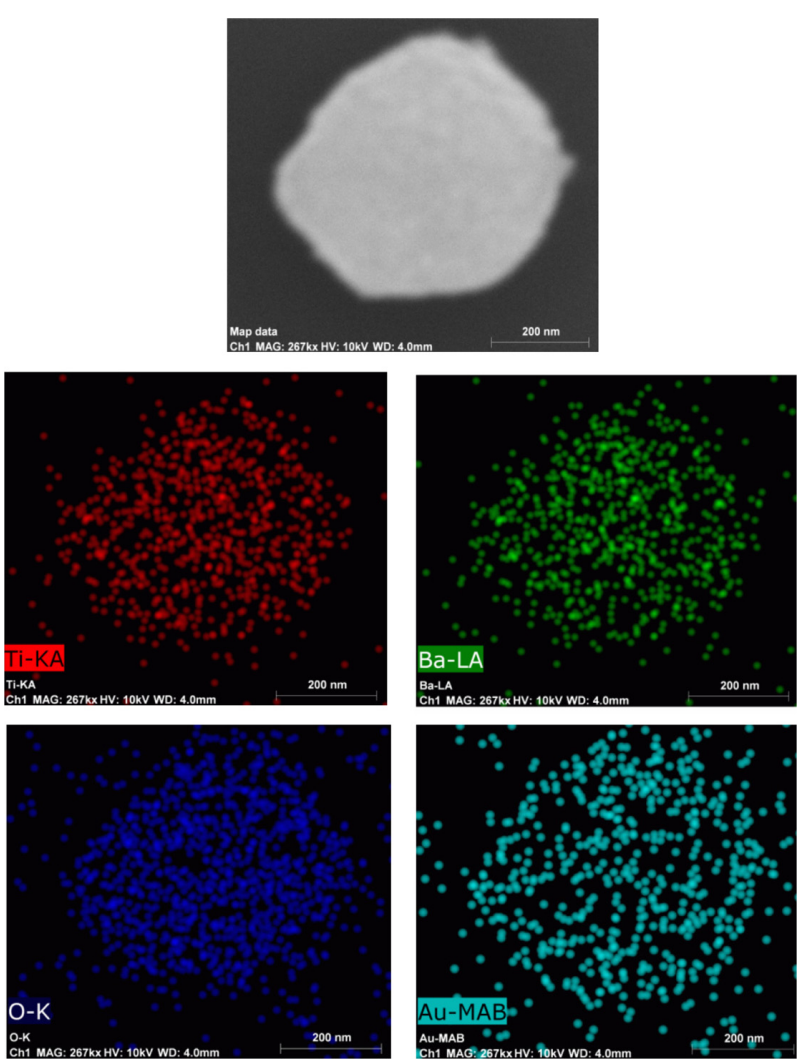

Figure SI SEM image and EDX analysis on a single nanoshell, showing its compostion in $\mathrm{Ti}, \mathrm{Ba}, \mathrm{O}$ and $\mathrm{Au}$.
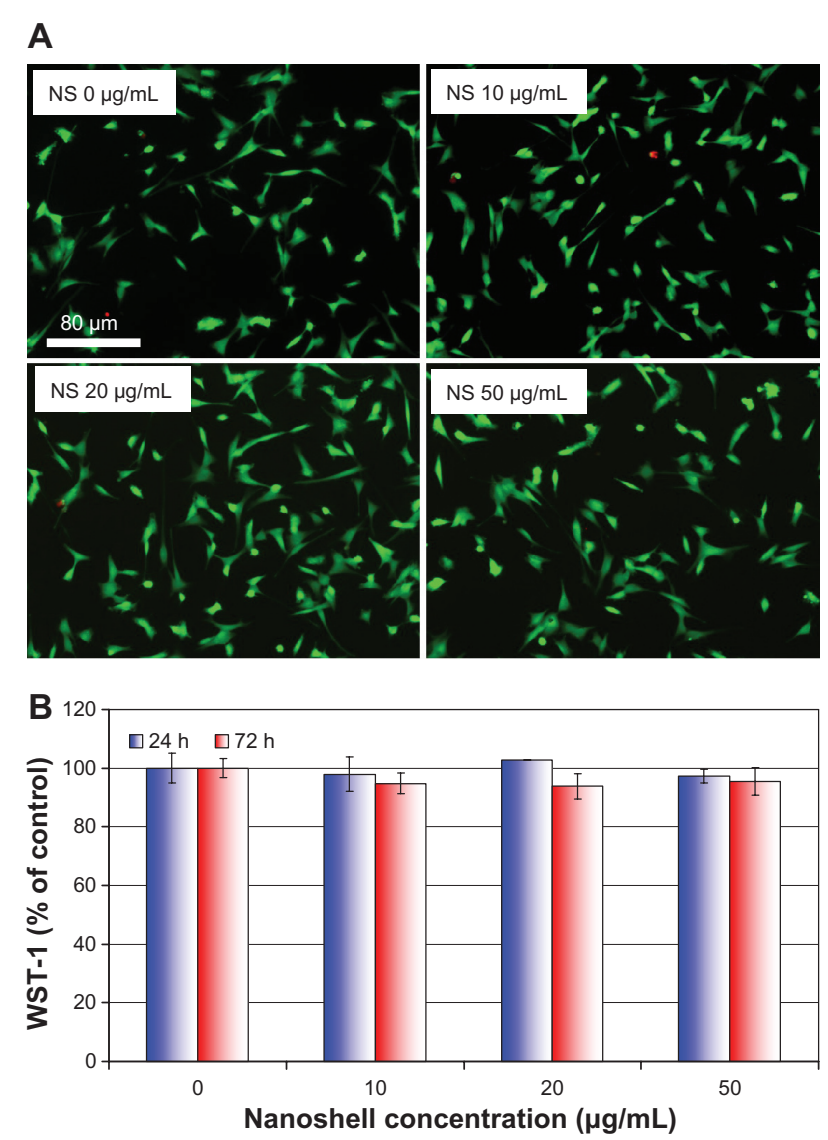

Figure S2 Cytocompatibility results on differentiatiating SH-SY5Y cells: the Live/ Dead assay (A) and WST-I assay at 24 and $72 \mathrm{~h}$ (B). 


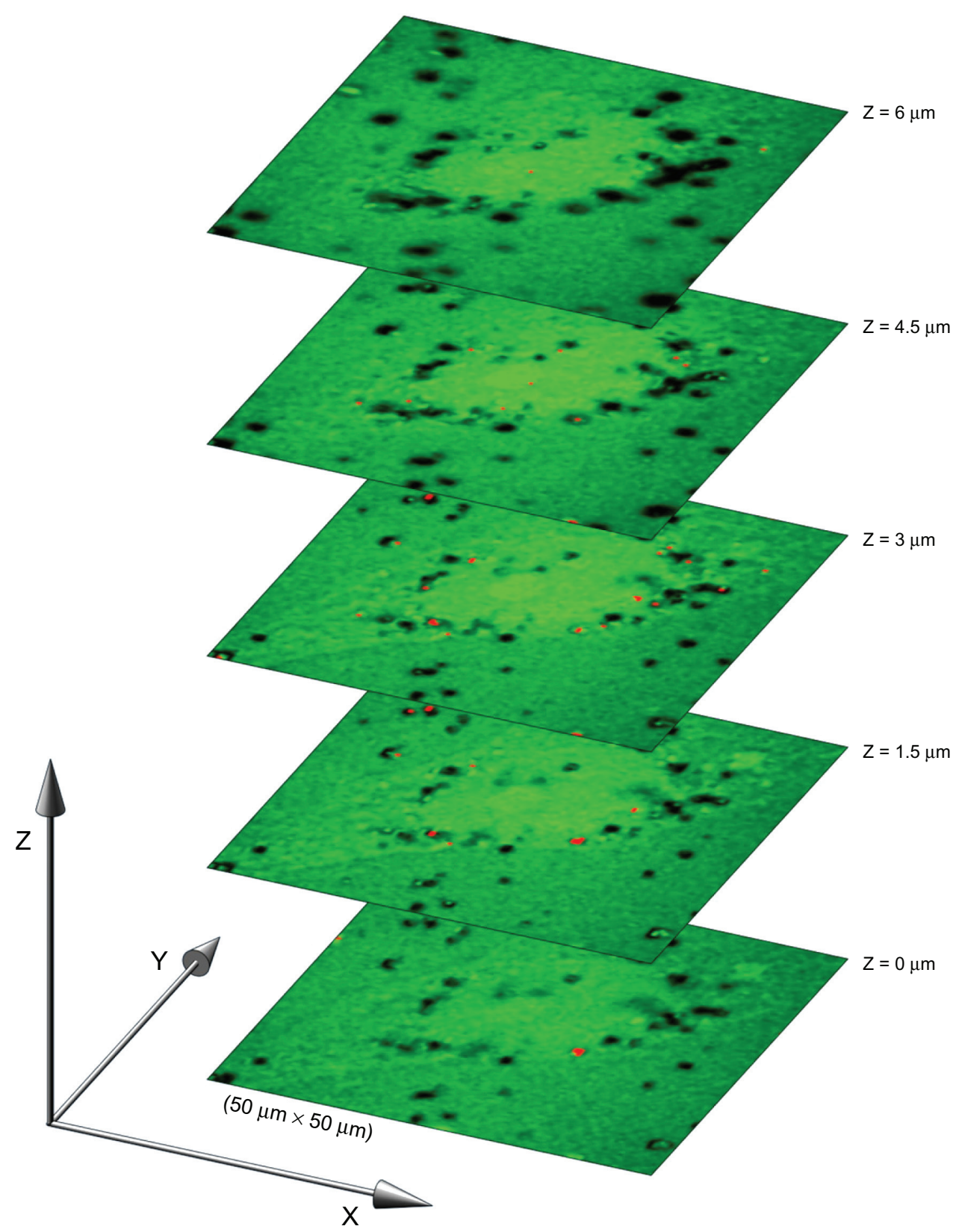

Figure S3 Example of CARS Z-stack acquisition of single cell including nanoshells. The green channel maps the intensity of the CARS signals from the $\mathrm{CH}_{2}$ bonds; the red channel labels the nanoshells. The field is $50 \mu \mathrm{m} \times 50 \mu \mathrm{m}$. 

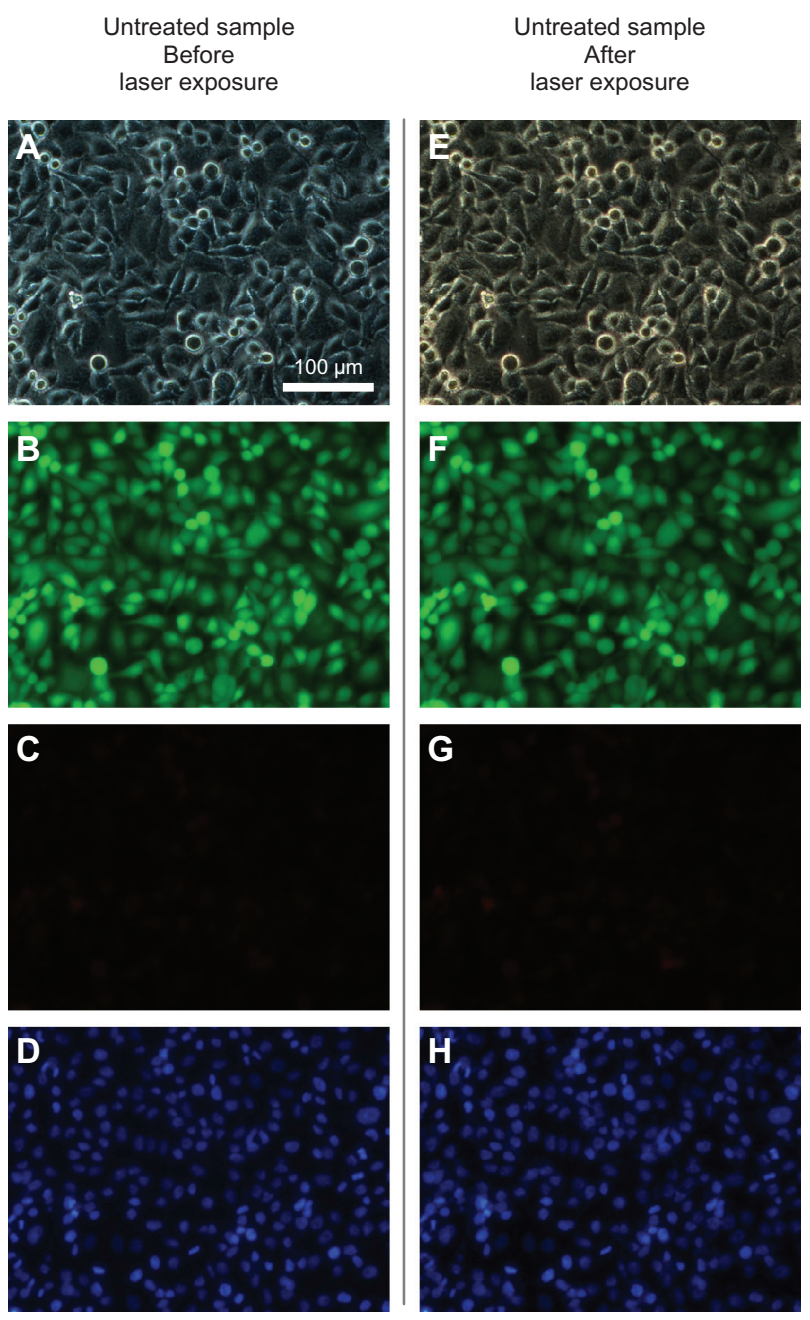

Figure S4 Neuroblastoma cells incubated without nanoshells before (left column, A-D) and after (right column, E-H) exposure to laser light. Cells are showed in bright field ( $\mathbf{A}$ and $\mathbf{E}$ ), labeled with calcein (in green, $\mathbf{B}$ and $\mathbf{F}$ ), with EthD-I (dead cells in red, $\mathbf{C}$ and $\mathbf{G}$ ), and with nuclei labeled with Hoechst (in blue, $\mathbf{D}$ and $\mathbf{H}$ ).

International Journal of Nanomedicine

\section{Publish your work in this journal}

The International Journal of Nanomedicine is an international, peerreviewed journal focusing on the application of nanotechnology in diagnostics, therapeutics, and drug delivery systems throughou the biomedical field. This journal is indexed on PubMed Central,

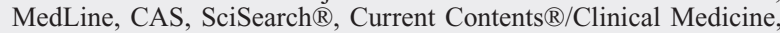

Journal Citation Reports/Science Edition, EMBase, Scopus and the Elsevier Bibliographic databases. The manuscript management system is completely online and includes a very quick and fair peer-review system, which is all easy to use. Visit http://www.dovepress.com/ testimonials.php to read real quotes from published authors.

\footnotetext{
Submit your manuscript here: http://www.dovepress.com/international-journal-of-nanomedicine-journal
} 